\title{
La lección de Gregorio Weinberg en la UNESCO o la impaciencia como virtud
}

Lessons by Gregorio Weinberg in UNESCO, or Impatience as a Virtue

Fernando Aínsa*

\section{Resumen}

Gregorio Weinberg colaboró con la UNESco durante más de veinte años en importantes proyectos como la Historia de la Humanidad y la Historia General de América Latina. Se recuerda con admiración y reconocimiento los hitos de esa colaboración y los de la amistad personal forjada a su socaire.

Palabras clave: Unesco; Historia Universal; América Latina; educación; ciencia.

\section{Abstract}

Gregorio Weinberg cooperated with UNESCO for over twenty years in important projects such as History of Humanity and General History of Latin America. The highlights of such cooperation and of personal friendship wrought under his protection are brought to mind with admiration and acknowledgement.

Key words: UNESCO; Universal History; Latin America; education; science.

Cuando en 1999 la UNESCo concedió a Gregorio Weinberg la medalla de plata de Aristóteles reconoció una parte de la deuda que la comunidad internacional tenía con quién le había entregado, no sólo una abierta visión historiográfica y un humanismo de profunda raíz social, sino un modelo íntegro y sin concesiones de cómo trabajar en equipo. Más de veinte años colaborando a diferentes niveles con la Organización de las Naciones Unidas para la Ciencia y la Cultura se refrendaban en esa medalla en cuyo anverso aparece el perfil del filósofo griego ejecutado a partir de una escultura conservada en el Kunsthistoriches Museum de Viena, y en su reverso la de una lechuza - símbolo de Atenea, diosa griega de la sabiduría-y una cita en griego antiguo del propio Aristóteles: "La energía de la mente es la esencia de la vida”.

\footnotetext{
*Ensayista. <fainsa@terra.es>
} 
Nadie mejor que Gregorio Weinberg para encarnar ese lema aristotélico. Porque fue esa energía la que mejor lo caracterizaba cuando lo conocí a finales de la década de los setenta en el marco de nuestro trabajo común en la UNESCO. Una energía mental avasalladora e incansable que le permitía asociar con envidiable agilidad mental temas y citas diversas y que hacía de su conversación un venero, no sólo de la sabiduría del filósofo e historiador, sino del polemista sagaz, de reacción centelleante y aguda. Era -en efecto- la energía mental la esencia de su vida, una vida que vivía intensa y nerviosamente, con una impaciencia en la que traducía su rigurosa exigencia con los demás y consigo mismo.

En esos años -inicialmente sombríos en la Argentina- Weinberg se consagró en la UNESCO a una doble tarea como historiador: la concepción y elaboración de la Historia Científica y Cultural de la Humanidad, decidida en 1978 por la Conferencia General de la Organización y proyectada en siete volúmenes y la Historia General de América Latina, decidida poco después y que debería tener nueve volúmenes. Como único miembro latinoamericano de la Comisión Internacional encargada de preparar la historia de la Humanidad, Weinberg debió batirse para que el plan de la obra tuviera en cuenta una región del mundo generalmente marginada. No sólo en nombre del regionalismo que hubiera podido reivindicar legítimamente, sino por entender que los valores del universalismo no pueden limitarse a la proyección de una visión etnocéntrica de raíz europea con la que tiende a asimilarse. Weinberg repetía convencido, citando al pensador francés del siglo XVIII, Dupont de Nemours: "no debemos confundir nuestro horizonte mental con los límites del mundo".

\section{América Latina en el mundo}

Un lugar de América Latina en la historia universal que reivindicaba con el mismo énfasis con que lo hacía con Asia, otra región del mundo en ese momento postergada. A modo de gráfico ejemplo gustaba citar en forma paralela al Popol Vuh y al Ramayana. En ese recentramiento "multipolar" de la visión histórica que propugnaba, Weinberg no prescindía ni minimizaba el patrimonio del pensamiento clásico occidental, sino que, por el contrario, lo enriquecía al abrirlo a 
otras culturas. No se trataba de postergar sus valores, sino de incorporar los de otras civilizaciones a un acervo común de la humanidad. $\mathrm{Y}$ a eso se atuvo con fervorosa dedicación.

Como integrante del Comité de la Historia General de América Latina —que presidía el historiador venezolano Germán Carrera Damas- Weinberg se preocupó de que el proyecto -concebido como un esfuerzo de comprensión de América Latina desde su propia perspectiva- no se tradujera en aislacionismo historiográfico o en una subestimación del papel desempeñado por la historia mundial en la que, de todos modos se integra la del continente americano. Tampoco -repetía en el Comité- debía prescindirse del esfuerzo de la visión que los otros han tenido sobre la realidad latinoamericana, esfuerzo de comprensión a la que no debía ser ajena la "simpatía" concebida en su generoso sentido etimológico.

Esta visión inclusiva y abierta de la historia no se limitaba a aspectos políticos, económicos o culturales. Weinberg insistía con una clarividencia que el tiempo confirmaría, en integrar el conocimiento científico al humanismo. Destacaba -como luego haría en uno de sus libros fundamentales, La ciencia y la idea de progreso en América- cómo en el Nuevo Mundo el afianzamiento de los estados nacionales no se había correspondido con una nacionalización de la ciencia, aunque la ciencia haya tenido también sus "héroes y mártires", patrimonio que debía ser incorporado al conocimiento historiográfico y contextualizado con su época.

En esas reuniones de los Comités de ambas historias, celebradas en París, conocí a Gregorio Weinberg. Sus intervenciones, ajenas a tópicos en boga o a esquemas ideológicos, me habían sorprendido y, cuando me lo presentó un común amigo, Javier Fernández, -hombre generoso como pocos, Ministro Consejero en la Delegación Argentina ante la Organización- sentí que estaba conociendo a un Maestro, en el difícil sentido clásico de la palabra: el hombre que forma e influye, el orientador y el guía; un ser cuya sabiduría no se limita al conocimiento libresco o a las clases impartidas en un aula escolar o universitaria, ese alguien capaz de enfrentar con el solo poder de su palabra a dictaduras y arbitrarios ejercicios de autoridad, un hombre que tiene devotos discípulos; en resumen, el que funda "una escuela" con sus seguidores y sus detractores.

Algo similar me había sucedido con Leopoldo Zea, pero con Gregorio Weinberg se dio rápidamente la confianza y la familiaridad que se 
puede inicialmente atribuir a nuestra común weltanschauung rioplatense, esa visión del mundo íntima y dinámica que podíamos compartir desde las dos orillas, argentina y uruguaya, que tanto nos aproximan cuando vivimos lejos. Poco después descubrí que había algo más: la exultante juventud que dimanaba de su inquieta curiosidad, su impaciencia proverbial, eliminaba la barrera de la edad que podía separarnos y nos aproximaba en una complicidad que pronto fue camaradería. Con los años, Weinberg sería para mí el tío jovial e inteligente que no había tenido nunca y con el que inútilmente había soñado en mi orfandad familiar. Juntos recorríamos las librerías de París, intercambiábamos títulos e ideas, hacíamos de copiosos almuerzos auténticos foros que para mí fueron de aprendizaje de ese "pensamiento crítico" que ejercía sin claudicaciones ni concesiones a los dictados de la moda.

\section{Las galerías secretas de la amistad}

Como en las "galerías secretas" de Cortázar que comunican en forma subterránea París con Buenos Aires, se invirtió el esquema cuando, restablecida la democracia, lo visitaba en mis viajes profesionales a la Argentina. Referente obligado, cita obligatoria era compartir aquel mismo itinerario parisino por librerías (generalmente nos encontrábamos en la de los hermanos Platero de la calle Talcahuano) y parrilladas porteñas (recuerdo las de la calle Montevideo). Entre uno y otro momento -los encuentros en una $u$ otra ciudad- la correspondencia postal suplía la ausencia y el intercambio de libros, el de ideas expresadas de viva voz. Seguíamos en contacto -eso era lo importante- y así se concretó su participación en un libro de gestación difícil, América Latina en sus ideas, publicado en 1986 y coordinado por Leopoldo Zea, donde la contribución de Weinberg fue fundamental no sólo por el capítulo que redactó sobre "El universo de la educación como sistema de ideas en América Latina", sino por sus aportes a la concepción general del volumen. De ahí surgió el proyecto de publicar su obra fundamental, Modelos educativos en la historia de América Latina, actualizada para la UNESCO, lo que se haría en coedición argentina con A/Z, un título que mantiene tan vivo su pensamiento como su memoria. 
Casi veinte años más tarde se empezarían a publicar los primeros volúmenes de la Historia científica y cultural de la Humanidad. Poco después, los de la Historia General de América Latina. Gregorio Weinberg, en su exigente impaciencia, no podía entender cómo un tan considerable esfuerzo intelectual y financiero de la UnESCO se disolvía en demoras burocráticas, desinterés oficial, para finalmente interrumpirse. A la fecha de su muerte -en abril del 2006- sólo se habían publicado cinco volúmenes de ambos proyectos. Para el resto, no hay fecha anunciada, ni responsable capaz de dar alguna información.

Gregorio Weinberg no podía aceptarlo y una cierta amargura trasuntó nuestra última conversación, en marzo del 2004, cuando yo ya había dejado de trabajar en la Organización cuatro años antes. Porque además de ser un historiador capaz de ir a la raíz de los acontecimientos con una perspectiva de humanismo ético y social indiscutible, Weinberg era un editor que conocía bien las dificultades del oficio y sabía cómo hacerles frente. Docenas de títulos lo respaldaban en colecciones que son referencia obligada del "pasado argentino" que había rescatado y mantenía vivo. Comprendí en ese momento en que, incansable, emprendía la dirección de otra aventura editorial -Nueva Dimensión Argentina- que la impaciencia, bien entendida, puede ser una virtud. En todo caso, lo era en el suyo, que había hecho de la "energía de la mente" la esencia de su vida. 